\title{
SEISMIC VERIFICATION METHOD FOR STEEL BRIDGE PIERS WITH PIPE SECTION UNDER TWO DIRECTIONAL EARTHQUAKE COMPONENTS
}

\author{
Nishigandha KULKARNI ${ }^{1}$ and Akira KASAI ${ }^{2}$ \\ ${ }^{1}$ Dept. of Civil Eng., Nagoya University (Furo-cho, Chikusa-ku, Nagoya 464-8603, Japan) \\ E-mail: kulkarni@civil.nagoya-u.ac.jp \\ ${ }^{2}$ Member of JSCE, Assoc. Professor, Dept. of Civil and Env. Eng., Kumamoto University \\ (2-39-1, Kurokami, Chuo-ku, Kumamoto 860-8555, Japan) \\ E-mail: kasai@kumamoto-u.ac.jp
}

\begin{abstract}
This work deals with influence of bi-directional cyclic displacement loading on the ductility of hollow circular steel columns and to develop a seismic verification method for bridge piers, with pipe sections, when subjected to coupling action of two horizontal earthquake components. For this purpose, nonlinear numerical analyses are performed on Finite Element models by setting radius-thickness ratio and slenderness ratio as main design parameters. The strain-based ductility formulas are developed separately for uni- and bi-directional cyclic loadings, and based on these formulas a seismic verification method is proposed. To confirm this method, nonlinear dynamic analyses are carried out on three different beam element models of bridge piers. The deformation and strain performances are evaluated by displacement-based and strain-based methods. The comparative study shows that the strain-based seismic verification method is critical than displacement-based method. Further, comparison between allowable values given by past ultimate strain formula indicates that the formulas developed in the present study are more adequate for use in seismic verification of circular steel bridge piers when subjected to two directional earthquake components at the same time.
\end{abstract}

Key Words : steel circular bridge piers, bi-directional cyclic loadings, ultimate strain formulas, seismic design method, dynamic verification

\section{INTRODUCTION}

In Japan, steel pipe sections are popularly used in highway bridge support system and they are assumed to behave like a cantilever column. However, these steel piers are found to be vulnerable to strength and ductility reduction when local buckling occurs at the base of the pier due to earthquakes. This type of damages was observed in the (1995) HyogokenNanbu Earthquake ${ }^{1)}$. After this instance, Japanese Seismic Design Specifications for highway bridges has been revised in 1996 and 2002 including the (1995) Hyogoken-Nanbu Earthquake as a strong earthquake and performance-based design concept respectively ${ }^{2)-4)}$. According to this performancebased concept, damages of the steel bridge piers are controlled in such a way that their performances under the input earthquake components remain within the allowable limits ${ }^{5}$.

Since last few decades' research studies have been contributed in prediction of the allowable limit values which are also called as capacity of the steel columns by conducting experiments and numerical analysis. In early investigations ductility capacities in terms of strain were defined by applying compression and bending loads on the short cylinders and box stub columns considering that local buckling takes place within effective failure region which controls the ultimate ductility of the column ${ }^{6)-8}$. Whereas, ductility capacity formulas in terms of displacement were proposed by applying uni-directional cyclic loadings on the steel pipe or box section columns ${ }^{9), 10)}$ and which are then used as allowable limits when earthquake components are applied in one direction. However, large amplification in response of bridge piers due to coupling of two perpendicular earth- 
quake components was observed when compared to one directional response ${ }^{11), 12)}$. Therefore, number of research were started to investigate behavior of bridge piers under various patterns of bi-directional cyclic loadings such as square, diamond, circular, plus etc. on the steel columns ${ }^{13)}$. Among them cyclic circular pattern was found to be severe for pipe section columns and hence adopting this pattern, empirical formulas were proposed for ultimate strength and displacement-based ductility ${ }^{14), 15)}$. The concept of application of these ductility formulas in bi-directional seismic verification process was first introduced in author's previous study ${ }^{15)}$ and it was realized that application of this verification process became little complicated since, displacement- response of top of bridge pier always spreads randomly in two perpendicular directions when subjected to two horizontal earthquake components simultaneously. At the same time it was noticed that, average compressive strain-response pattern of bridge pier is easier for seismic verification than that of displacement-response. Therefore, it becomes essential to develop a seismic verification method based on strain ductility formulas for hollow circular steel bridge piers subjected to uni- as well as bi-directional cyclic loading.

The present work is organized as follows: initially, the numerical analyses are carried out for two types of Finite Element (FE) models, 1) shell element, 2) beam element models constructed for hollow steel circular columns and then they are subjected to horizontal uni- and bi-directional cyclic displacement loadings with constant axial force. Material and geometric nonlinearity are also considered in analysis. The effect of radius-thickness ratio and slenderness ratio on strength envelop curves and effect of loading patterns on the ultimate strains in shell and beam element models are observed. Based on the parametric study results, ultimate strain formulas and seismic verification method are developed. Finally, one and two directional nonlinear dynamic analyses are carried to verify the proposed method.

\section{NUMERICAL METHOD}

\section{(1) Finite Element models}

Two types of Finite Element (FE) models are developed for thin-walled circular steel bridge piers as shown in Fig.1. The shell element models are used to account local buckling and beam element models are used when local bucking is not necessary to encounter. In the shell element models (see Fig.1(a)), shell elements are only adopted in $3 D$ (where, $D=$

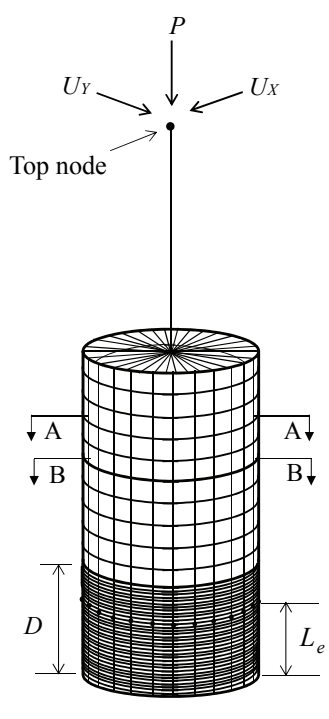

(a) Shell element model

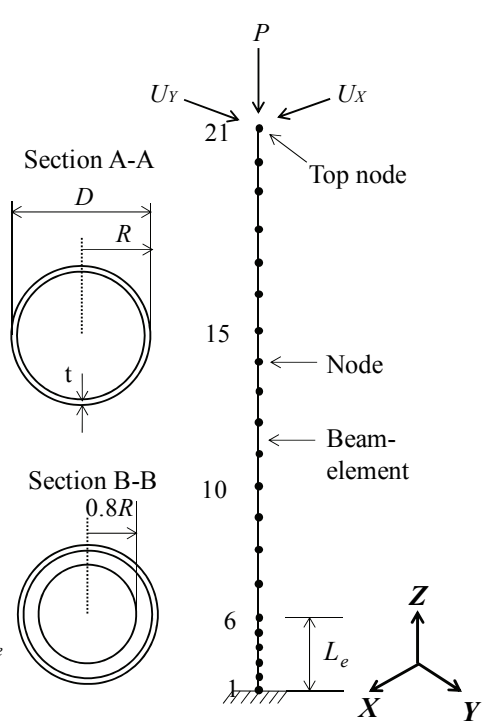

(b) Beam element model
Fig.1 Details of FE models used for analysis ${ }^{15)}$.

Table 1 Material properties of steel grade SM490 ${ }^{15}$.

\begin{tabular}{|c|c|c|c|c|c|c|}
\hline $\begin{array}{c}E \\
(\mathrm{GPa})\end{array}$ & $\begin{array}{c}\sigma_{y} \\
(\mathrm{MPa})\end{array}$ & $\begin{array}{c}\varepsilon_{y} \\
(\%)\end{array}$ & $\begin{array}{c}E_{s t} \\
(\mathrm{GPa})\end{array}$ & $\begin{array}{c}\varepsilon_{s t} \\
(\%)\end{array}$ & $v$ & $\begin{array}{c}\sigma_{u} \\
(\mathrm{MPa})\end{array}$ \\
\hline 200 & 315 & 0.157 & 6.67 & 1.10 & 0.3 & 490 \\
\hline
\end{tabular}

Table 2 Range of design parameters considered for circular steel columns.

\begin{tabular}{|c|c|}
\hline Parameter & Range \\
\hline$R_{t}$ & $0.050,0.060,0.075,0.090$ \\
\hline $\bar{\lambda}$ & $0.2,0.4,0.6$ \\
\hline$P / P_{y}$ & $0.0,0.05,0.10,0.15,0.20$ \\
\hline$t(\mathrm{~mm})$ & 20 \\
\hline
\end{tabular}

diameter of column) height from base and beam elements are used for remaining height. Rigid elements are added in between shell element part and beam element part to keep plane boundary condition and connectivity. The whole shell element part is circumferentially divided into 30 segments. And along the column height, first bottom most section is divided into 30 segments and remaining two sections are divided into 5 segments each. 10 beam elements are used to model upper beam element part. Ring type diaphragms are placed inside the shell element part at an interval of $D$, having inner diameter of $0.8 R$ ( $R=$ radius of pipe section) and thickness of $9 \mathrm{~mm}$. In beam element model (see Fig.1(b)), 5 segments are used up to effective failure height, $L_{e}$ (defined in 
2.(3)) and remaining height of column is modeled with 15 segments. A standard ABAQUS nonlinear FE software is used to develop and analyse the FE models $^{16)}$.

Timoshenko PIPE31 elements and reduced integration four-node general S4R elements available in ABAQUS element library are selected for beam elements and shell elements respectively. The nonlinear cyclic behaviour of SM490 grade steel is taken into consideration by applying modified two-surface material model (2SM) developed at Nagoya University $^{17)-20)}$ and its material properties are listed in Table 1 .

In the circular steel columns, basic design parameters are radius-thickness ratio $R_{t}$, slenderness ratio $\bar{\lambda}$ and axial force ratio $P / P_{y}$ which control occurrence of local buckling, overall stability and magnitude of compressive load in multiple of squash load $P_{y}$ respectively and they are defined as follows,

$$
\begin{gathered}
R_{t}=\sqrt{3\left(1-v^{2}\right)}\left(\sigma_{y} / E\right)(D / 2 t) \\
\bar{\lambda}=(2 h / r)(1 / \pi) \sqrt{\sigma_{y} / E}
\end{gathered}
$$

where, $\sigma_{y}=$ yield stress of steel, $E=$ Young's modulus, $v=$ Poisson's ratio, $t=$ thickness of plate, $h=$ column height and $r=$ radius of gyration of the cross section.

To understand influence of these design parameters on the ductility evaluation, specific ranges are selected and they are given in Table 2.

The numerical analyses are carried out using the modified Newton iteration technique combined with the displacement control method available in the ABAQUS program. In each analysis, the FE model is subjected to uni- or bi-directional cyclic horizontal displacement loadings $U_{X}$ and/or $U_{Y}$ with constant axial downward force simulating the weight of superstructure of magnitude $P$, as shown in Fig.1.

\section{(2) Loading pattern}

In the past studies it has been proved that circular bi-directional loading pattern is the most deteriorative pattern for the circular thin-walled steel columns, than others like diagonal, rectangular or diamond shaped bi-directional patterns ${ }^{14)}$. Therefore, circular loading patterns illustrated in Fig.2(b) and (c) similar to the authors previous work ${ }^{15}$, are adopted as bi-directional loading pattern which can be easily compared with conventional uni-directional pattern (see Fig.2(a)).

The horizontal displacement amplitude increasing in multiple of initial yield displacement, $\delta_{y}$ in each loading cycles is applied along with constant axial

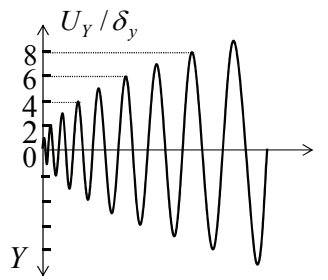

(a) $b / a=0(\mathrm{UNI})$

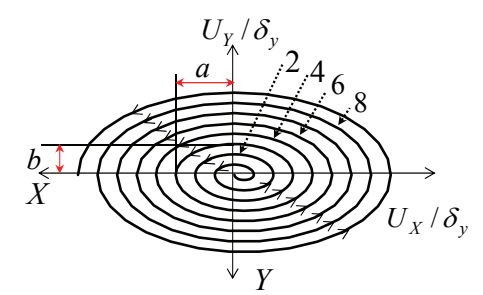

(b) $b / a=0.5$

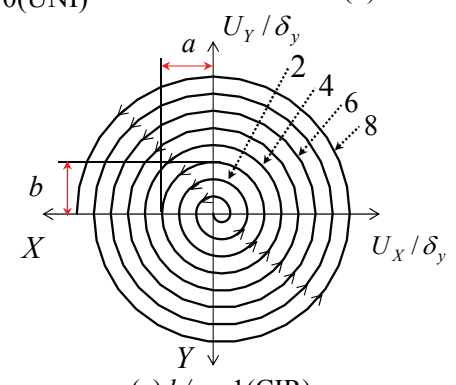

(c) $b / a=1(\mathrm{CIR})$

Fig.2 Uni- and Bi-directional cyclic loading patterns.

load at the top of the FE models. Where, $\delta_{y}=\left(H_{y} h^{3} / 3 E I\right)+\left(H_{y} h / \kappa G A\right)$ in which, $H_{y}=$ $\left(\sigma_{y}-P / A\right) Z / h=$ yield strength of column; $I=$ moment of inertia; $\kappa=$ transverse shear stiffness ratio for circular cross section $(=0.53) ; G$ and $Z=$ shear modulus and section modulus respectively. It should be noted that, each loading cycle is repeated only once. The governing equations of the loading trajectories of $U_{X} / \delta_{y}$ and $U_{Y} / \delta_{y}$ are given elsewhere ${ }^{15)} . b / a$ is the ratio of displacement amplitudes in $\mathrm{Y}$ direction to $\mathrm{X}$ direction as indicated in Fig.2(b) and (c), which controls the shape of the trajectory; e.g. when $b / a=0$, its a uni-directional loading (Fig.2(a)) and when $b / a=1$ it changes to cyclic circular bi-directional loading (Fig.2(c)).

\section{(3) Strain evaluation methods in FE models}

As in the present work, two types of FE models are considered, two separate strain evaluation methods are developed based on the axial deformations as follows.

\section{a) Equivalent strain in shell element model}

The local buckling region at the base part of the cantilever thin-walled steel column is the place where the material starts loosing the strength and undergoes yielding. Therefore, stress-strain behavior in this base part is very significant to decide the ultimate strength of the column. The length of this base part is defined as $L_{e}=1.2 D\left(1 / R_{t}{ }^{0.08}-1\right)$ and called as effective failure height ${ }^{21)}$. A procedure based on nodal deformation is developed here to obtain equivalent strain in the $L_{e}$ height of the shell element model. Fig.3(a) shows the enlarged cut section of shell el- 


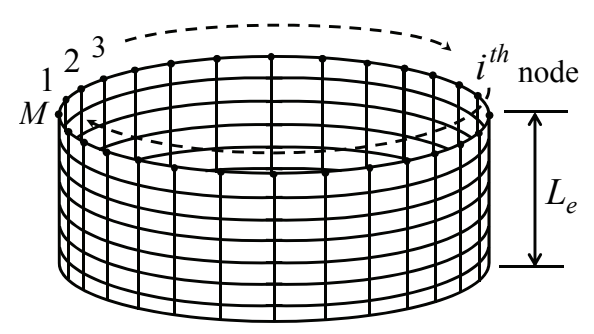

(a) Effective failure height section

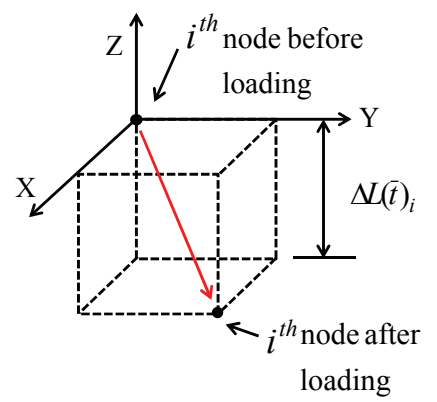

(b) Nodal deformation in X, Y, Z direction

Fig.3 Concept of equivalent strain evaluation in the shell element model.

ement model in which $M$ number of nodes are available at height $L_{e}$. After time $\bar{t}$ seconds, the $i^{\text {th }}$ node gets shifted in the space of $\mathrm{X}, \mathrm{Y}, \mathrm{Z}$ directions as shown in Fig.3(b). It can be seen that, the nodal deformation of the $i^{\text {th }}$ node in $\mathrm{Z}$ direction $\Delta L(\bar{t})_{i}$, is responsible for axial strain. Hence, $\mathrm{X}$ and $\mathrm{Y}$ directional deformations are ignored from strain calculation. Finally, the equivalent strain $\bar{\varepsilon}_{m s}$ can be evaluated by generating unique maximum envelop for $Z$ directional deformation of $M$ nodes $\operatorname{Max}\left(\Delta L(\bar{t})_{M}\right)$, and then dividing that by effective failure length $L_{e}$ as given in Eq.(3).

$$
\bar{\varepsilon}_{m s}=\operatorname{Max}\left(\Delta L(\bar{t})_{M}\right) / L_{e}
$$

\section{b) Average compressive strain in beam element model}

With the similar concept of equivalent strain adopted in the shell element model, an average compressive strain can be evaluated for beam element model, by calculating maximum compressive strain envelop from each integration point of a beam element and then averaging of such envelops for $N$ number of elements within the effective failure height, $L_{e}$. The detailed evaluation procedure is explained elsewhere ${ }^{15)}$. The mathematical expression for an average compressive strain $\bar{\varepsilon}_{m b}$ is given in Eq.(4), (a)

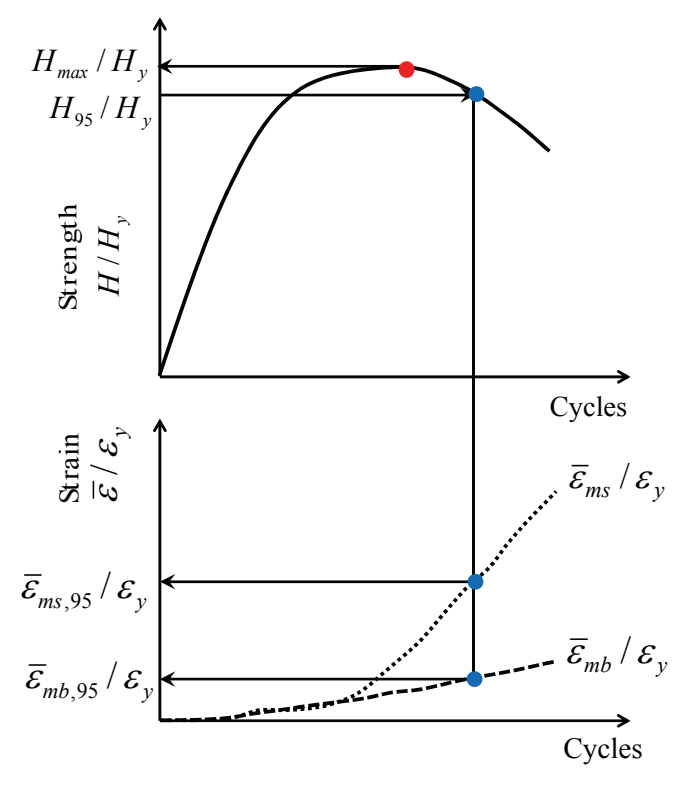

Fig.4 Definition of ultimate strength and ultimate stains.

$$
\bar{\varepsilon}_{m b}=(1 / N) \sum_{l=1}^{N}\left(\varepsilon_{l i}\right)_{\max }
$$

\section{(4) Concept of ultimate strength and ultimate strain}

During static analysis, each FE model is subjected to the cyclic lateral displacement with constant axial load and observations are taken for strength and strain.

The shell element models of steel columns are purposefully selected to include the local buckling effect into the ultimate strength quantity. However, ultimate strain values are measured from average compressive strain in the beam element models. Because, even if the concept of equivalent strain incorporates local buckling, it is based on nodal deformation in axial direction of column and not on the stress-strain behavior in individual shell element. On the other hand, average compressive strain concept represents stress-strain relationship at each integration point in the cross-section of beam element. Further, in most of the dynamic analysis, instead of shell elements, beam elements are usually preferred by engineers to construct the FE models of bridge systems which decrease complexity in modeling and also reduce analysis run time. Hence, concepts of FE modeling used in static analysis to predict the capacity and in dynamic analysis to find the demand both synchronize well with each other.

It is well known that, when the uni-directional loading is active in $X$ axis, then the column generates resisting force in $X$ direction $\left(H_{X}\right)$. On the other hand, when the bi-directional loading is applied, the 

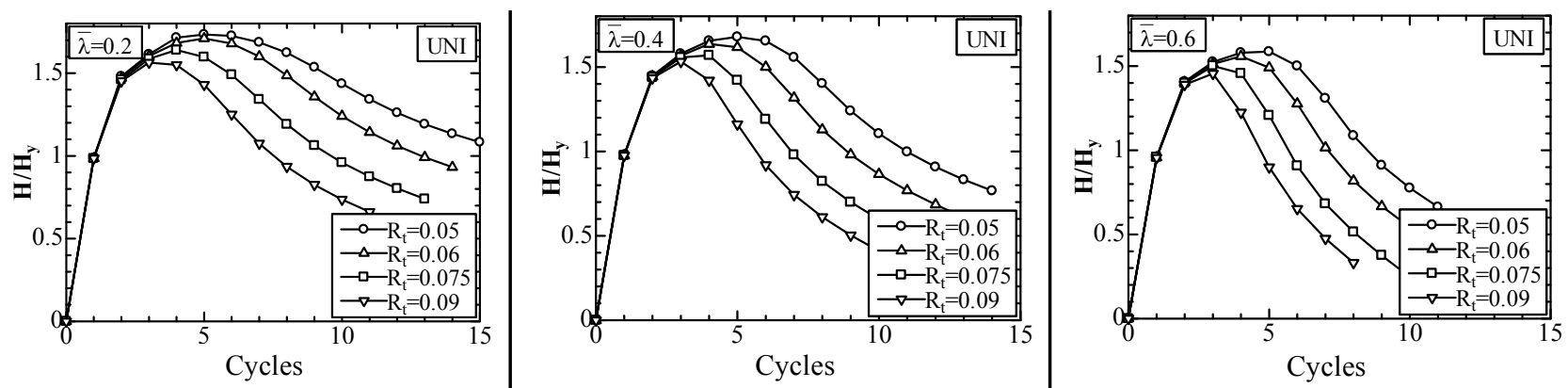

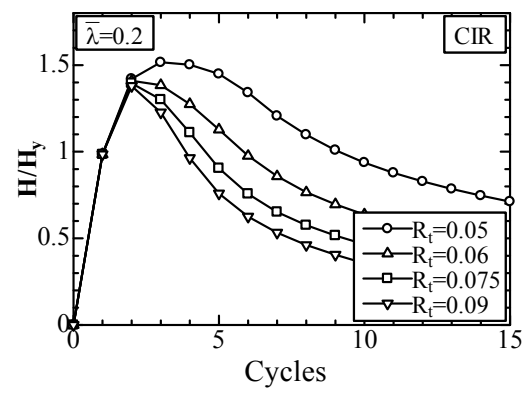

(a) At constant $\bar{\lambda}=0.2$

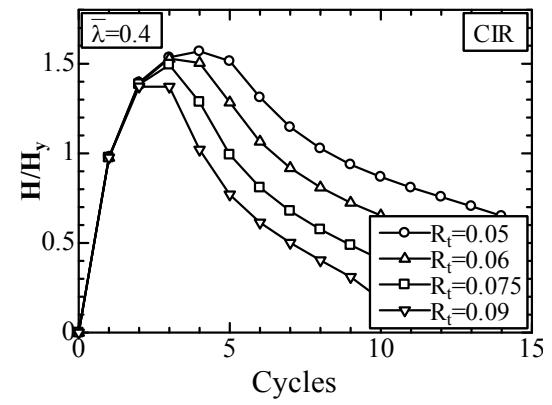

(b) At constant $\bar{\lambda}=0.4$

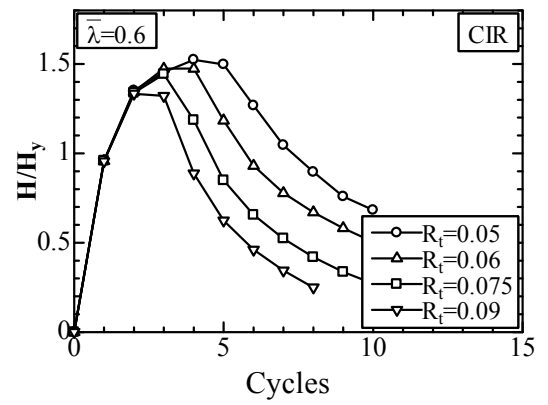

(c) At constant $\bar{\lambda}=0.6$

Fig.5 Effect of $R_{t}$ and $\bar{\lambda}$ on envelop curves of strength.

strength of the column gets distributed into $X$ and $Y$ directions as $H_{X}$ and $H_{Y}$. Therefore, a restoring strength term $H$ is introduced here and which is defined by $H=\sqrt{H_{X}^{2}+H_{Y}^{2}}$.

The restoring strength envelop plotted against the number of displacement cycles is shown in Fig.4(a). To define ultimate strength, it is recommended to select maximum strength point on the envelop curve $^{3), 22)}$, however, it has been found that even if ductility at the maximum strength is physically clear, it does not fully reflect plastic deformations. Whereas, ductility at $95 \%$ of maximum strength on post peak curve assumes to be a better option which accounts for complete use of steel strength at the stage of plastic deformation ${ }^{23)}$. Hence, in Fig.4(a), ultimate strength factor $H_{95} / H_{y}$ is marked on the post peak curve at $95 \%$ of $H_{\max } / H_{y}$. The envelop curves for equivalent strain factor $\bar{\varepsilon}_{m s} / \varepsilon_{y}$ and average compressive strain factor $\bar{\varepsilon}_{m b} / \varepsilon_{y}$ obtained from shell and beam element models respectively and they are shown in Fig.4(b). The ultimate strain factors $\bar{\varepsilon}_{m s, 95} / \varepsilon_{y}$ and $\bar{\varepsilon}_{m b, 95} / \varepsilon_{y}$ are the points on strain envelop curves corresponding to ultimate strength factor $H_{95} / H_{y}$. This ultimate strain evaluation procedure is carried out for each case of circular steel columns mentioned in Table 2 and resulting values are used to create ductility formulas.

\section{RESULTS AND DISCUSSIONS}

\section{(1) Effect of radius-thickness ratio and slender- ness ratio on envelop curves of strength}

In Fig.5, the envelop curves of strength versus number of displacement cycles are plotted for single case of axial force ratio, $P / P=0.10$ and only two loading patterns as, uni-directional and circular bi-directional (hereafter referred as UNI and CIR respectively) are considered. The main observations from Fig.5 are as follows.

(1) In both UNI and CIR loading patterns, it is seen that maximum strength decreases as $R_{t}$ increases, irrespective of $\bar{\lambda}$.

(2) Concerned with UNI loading, it is found that as $\bar{\lambda}$ increases the post peak curves becomes steeper. Whereas, in the case of CIR loading and $\bar{\lambda}=0.2$, it shows rapid decrease in strength after peak than that of cases $\bar{\lambda}=0.4$ and 0.6 .

(3) When compared between UNI and CIR loading effect, CIR loading lowers down maximum strength carrying capacity of columns irrespective of $R_{t}$ and $\bar{\lambda}$.

Above observations prove that, not only radius-thickness ratio and slenderness ratio, but the type of loading pattern also makes considerable impact on strength behavior of the columns.

\section{(2) Effect of loading patterns on ultimate strains}

To understand the effect of bi-directional cyclic loading on ultimate strain behavior of both shell 


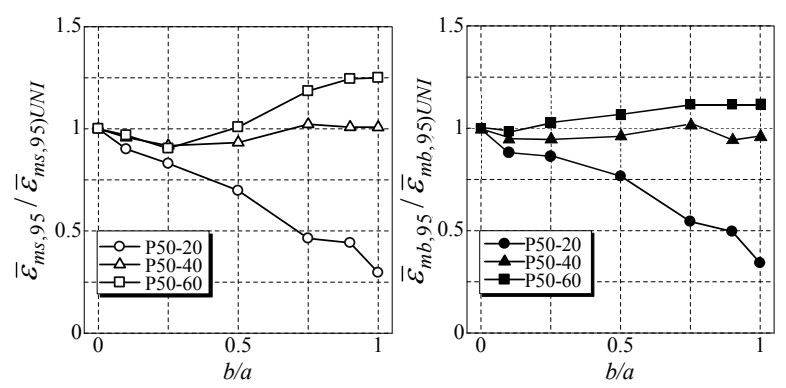

(a) At constant $R_{t}=0.05$

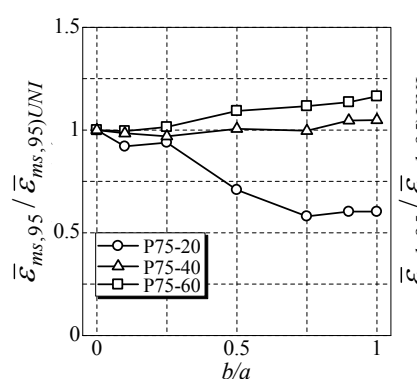

(c) At constant $R_{t}=0.075$

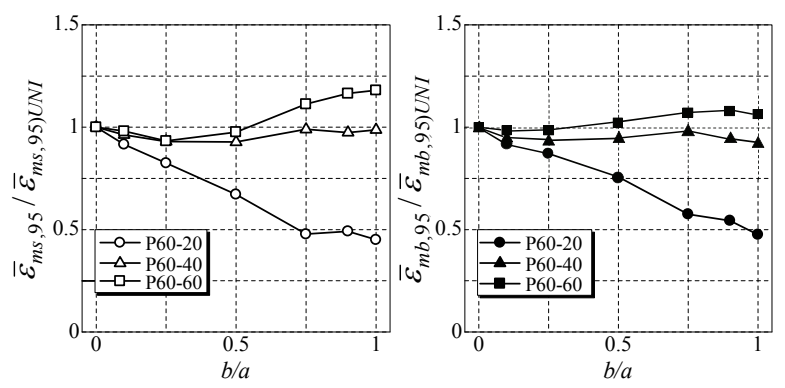

(b) At constant $R_{t}=0.06$
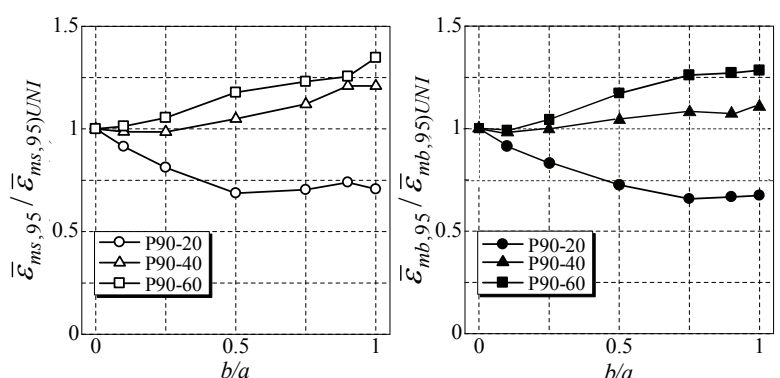

(d) At constant $R_{t}=0.09$

Fig.6 Effect of loading patterns on the ultimate strain ratios.

element and beam element models, seven loading patterns are considered by selecting $b / a$ ratio values as $0,0.1,0.25,0.5,0.75,0.9,1.0$, which include UNI and CIR patterns and unique case of axial force ratio $P / P_{v}=0.15$ is considered.

The graphs for the ultimate strains normalized by ultimate strains of UNI loading on vertical axis and $b / a$ on horizontal axis are illustrated in Fig.6, in which the left side graphs are for equivalent strain factors i.e. $\bar{\varepsilon}_{m s, 95} / \bar{\varepsilon}_{m s, 95) U N I}$ whereas, right side graphs are for average compressive strain factors i.e. $\bar{\varepsilon}_{m b, 95} / \bar{\varepsilon}_{m b, 95) U N I}$. In Fig.6, FE models are identified by their corresponding $R_{t}$ and $\bar{\lambda}$ values, e.g. P75-20 means, pier having $R_{t}=0.075$ and $\bar{\lambda}=0.2$. Some of the significant observations from Fig.6 are summarized as follows,

(1) The effect of the ratio $b / a$, on the behavior of ultimate equivalent and average compressive strain factors has shown considerable similarity. This means that, shell element and beam element models perform in similar way almost for all cases of the columns shown in Fig.6.

(2) In each graphs of Fig.6, it is observed that, as the loading pattern changes from $b / a=0$ to $b / a=1$, ultimate strain for the short columns (i.e. $\bar{\lambda}=0.2$ ) goes on decreasing than its uni-directional ultimate strain. Whereas, for the medium and long columns (i.e. $\bar{\lambda}=$ $0.4,0.6)$ that respectively remains nearly constant and increases gradually. This means, slenderness ratio is an important parrmeter in ultimate behavior of the columns and which further involves its significance in the ductility formulation.

To understand the reason behind this observed phenomenon for various slenderness ratios, it is required to investigate in detail the strain behavior in the columns at their ultimate states. For this purpose, contour plots obtained from ABAQUS/CAE ${ }^{24)}$ are used here to compare strain in shell element models. The averaging method available in ABAQUS/CAE is employed to generate the strain contour plots which calculate average values at nodes common to two or more contributing elements. The average threshold percentage is assigned to $75 \%$ to confirm smoother effect with less discontinuities from element to element.

The contour images for logarithmic normal strain $\varepsilon_{z}^{L}$, in the direction of local axis of an element parallel to $Z$ axis of column and logarithmic shear strain $\gamma^{L}$, in the direction of mutually perpendicular local axes along the plane of the shell element, are shown in Fig. 7 and 8 respectively, for the P75-20, P75-40 and P75-60 models. To identify the actual averaged maximum normal and shear strain in the shell elements at the ultimate state of the column, the absolute maximum strain values $\left|\varepsilon_{z}^{L}\right|_{\max }$ and $\left|\gamma^{L}\right|_{\max }$ shown in the red boxes are taken from each legend of contour plots and then they are normalized by normal yield strain $\varepsilon_{y}$ and shear yield strain $\gamma_{y}\left(\gamma_{y}=\tau_{y} / G\right.$ 

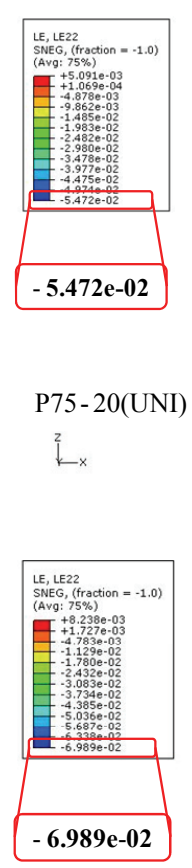

P75 - 40(UNI)
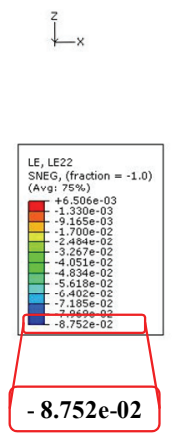

P75 - 60(UNI)

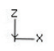

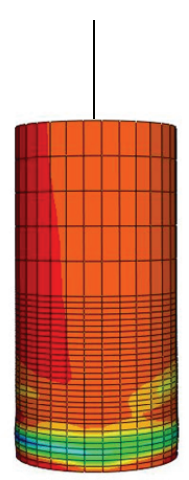

(a) At constant $\bar{\lambda}=0.2$
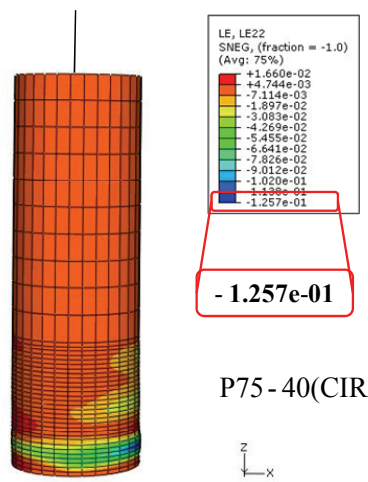

P75 - 40(CIR)

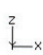

(b) At constant $\bar{\lambda}=0.4$

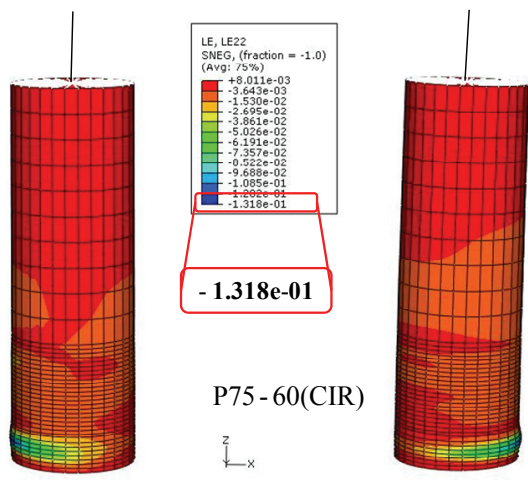

(c) At constant $\bar{\lambda}=0.6$

Fig.7 Contour plots for logarithmic normal strain $\varepsilon_{z}^{L}$.
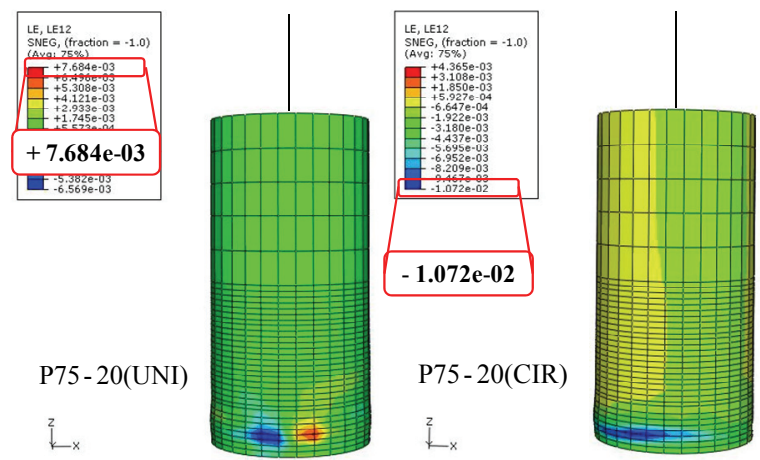

(a) At constant $\bar{\lambda}=0.2$
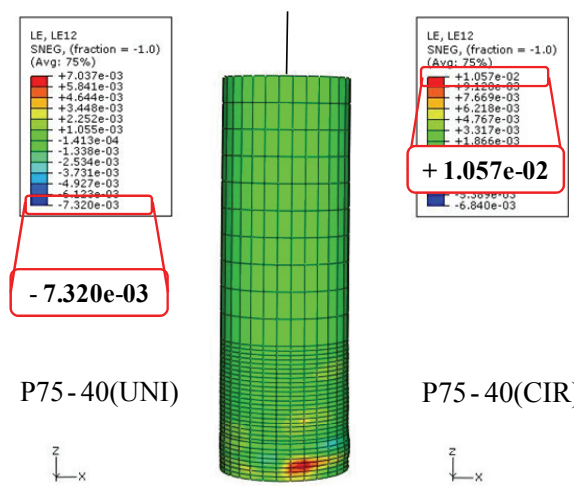

P75 - 40(CIR)
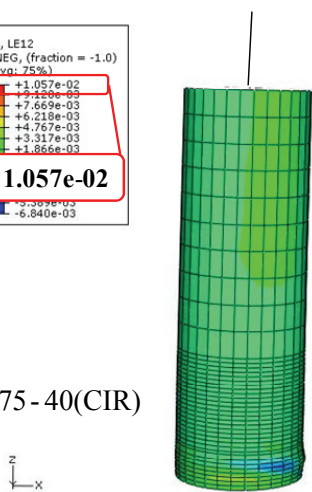

(b) At constant $\bar{\lambda}=0.4$
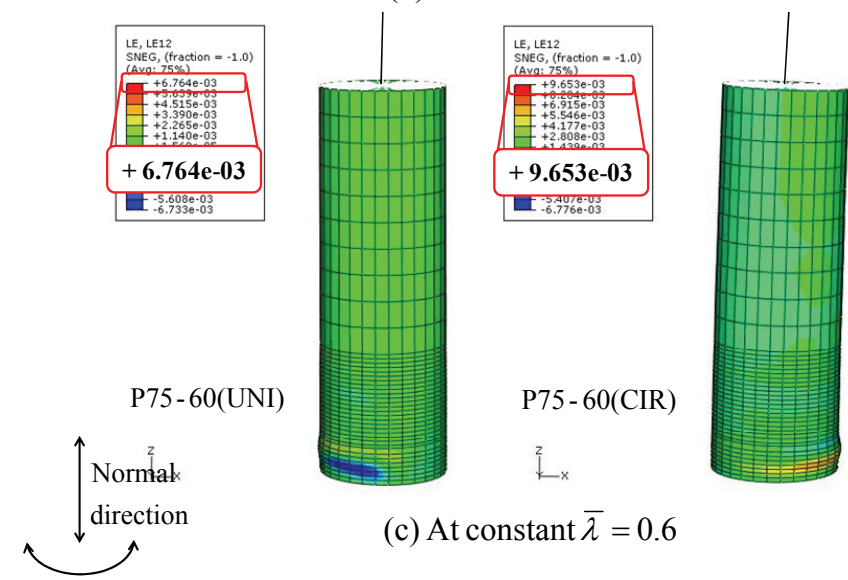

(c) At constant $\bar{\lambda}=0.6$

Fig.8 Contour plots for logarithmic shear strain $\gamma^{L}$ where, $\tau_{y}=$ yield shear stress and $G=$ shear modulus) respectively which are tabulated in Table 3 for UNI and CIR loadings. The major findings from this investigation are as follows,

(1) The logarithmic normal strain factor $\left|\varepsilon_{z}^{L}\right|_{\max } / \varepsilon_{y}$ which considers tension and compression mechanism, increases as the slenderness ratio $\bar{\lambda}$ increases for both UNI and CIR loadings.

(2) On the other hand, the logarithmic shear strain factor $\left|\gamma^{L}\right|_{\max } / \gamma_{y}$ which accounts for sliding action, decreases as the height of column increases.

From this comparison between strain behaviors in columns with different slenderness, it can be stated that, in short columns shear strains are dominant at their ultimate state and as loading changes from UNI to CIR this strain becomes even larger. Hence, decreasing trend of the ultimate strains was observed in Fig.6 for short columns, in which strain values are calculated from movement of nodes in normal direction and not in the shearing direction. However, for the medium and long columns normal strains are dominant at their respective ultimate states. Therefore, constant and gradually increasing trends were observed in Fig.6, as loading changes from UNI to CIR for medium and long columns respectively. 
Table 3 Normalized absolute maximum logarithmic normal and shear strains in shell element models.

\begin{tabular}{|c|c|c|c|c|}
\hline \multirow{2}{*}{} & \multicolumn{2}{|c|}{$\begin{array}{c}\text { (a) Normal strain } \\
\left|\begin{array}{c}L \\
\varepsilon_{z}\end{array}\right|_{\max } / \varepsilon_{v}\end{array}$} & \multicolumn{2}{c|}{$\begin{array}{c}\text { (b) Shear strain } \\
\left.\gamma^{L}\right|_{\max } / \gamma_{v}\end{array}$} \\
\hline \multirow{2}{*}{ Models } & \multicolumn{2}{|c|}{ Loading pattern } & \multicolumn{2}{c|}{ Loading pattern } \\
\cline { 2 - 5 } & UNI & CIR & UNI & CIR \\
\hline P75-20 & 34.85 & 41.96 & 3.25 & 4.54 \\
\hline P75-40 & 44.52 & 80.06 & 3.10 & 4.47 \\
\hline P75-60 & 55.75 & 83.95 & 2.87 & 4.09 \\
\hline
\end{tabular}

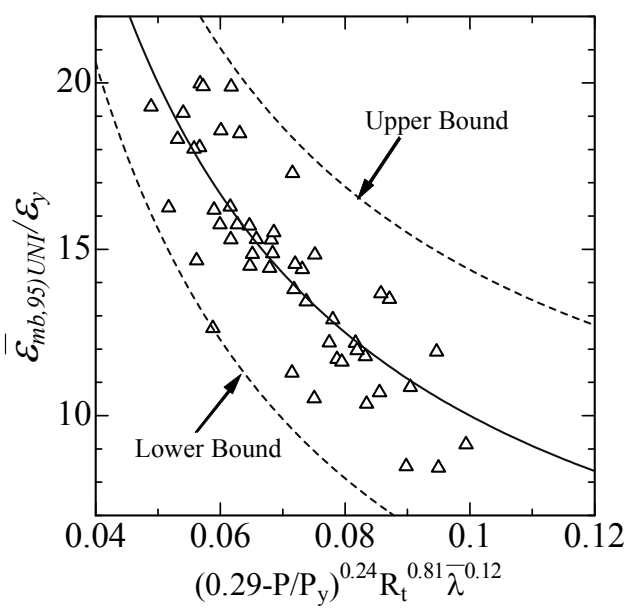

(a) Cyclic uni-directional loading

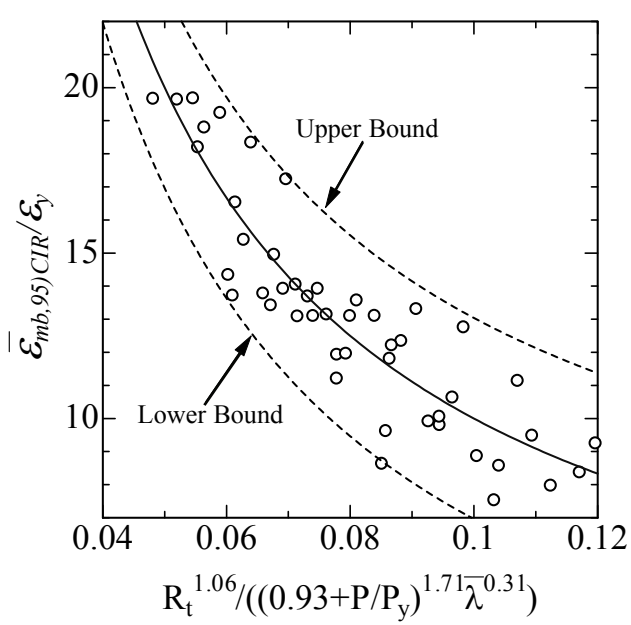

(b) Cyclic circular bi - directional loading

Fig.9 Proposed ultimate strain formulas for circular steel columns.

\section{(3) Ductility formulation and seismic verification method}

\section{a) Ultimate strain formulas}

The modified two-surface material constitutive law which is used in the present study is basically developed to capture cyclic behavior of structural steel especially in the yield plateau. The applicability of the 2SM was confirmed by comparing experi- mental and analytical results for uni-directional cyclic loading on circular and box steel columns ${ }^{9), 10)}$. Hence, it is believed that the performance of 2SM in bi-directional loading on circular steel columns is well accepted.

The ultimate strain formulas developed for steel columns so far, were only concerned to the strain behaviour in the critical part of the column i.e. effective failure region ${ }^{6), 7)}$. Therefore, the effect of the entire height of the column i.e. the slenderness ratio was not considered. However, in the present work, it is found that slenderness ratio has significant effect on the ductility in terms of strain. Therefore, $R_{t}, \bar{\lambda}$ and $P / P_{y}$ are very important parameters to get involved in ultimate strain formulation. Moreover, in the past study, the FE models using shell elements were constructed for the critical part of the column and analyzed for compression and bending loads so as to consider local buckling effect in the ductility formulation. Whereas, in the present work, the ultimate strain formulas are derived from the strain observations of beam element models. This ensures coordination between FE modeling used in the ductility prediction process and seismic design process i.e. dynamic analysis.

The ultimate average compressive strain factors $\bar{\varepsilon}_{m b, 95) U N I} / \varepsilon_{y}$ and $\bar{\varepsilon}_{m b, 95) C I R} / \varepsilon_{y}$ are plotted against a combined value of $R_{t}, \bar{\lambda}$ and $P / P_{y}$ as shown in Fig.9(a) and (b), respectively. These combined values are determined from the nonlinear regression analysis. Eq.(5) and (6) are written for ultimate strains in UNI and CIR loading cases fitted for $99 \%$ and $97 \%$ confidence levels respectively.

$$
\begin{gathered}
\frac{\bar{\varepsilon}_{m b, 95) U N I}}{\varepsilon_{y}}=\frac{1}{\left(0.29-P / P_{y}\right)^{0.24} R_{t}^{0.81} \bar{\lambda}^{0.12}} \pm 4.13 \leq 20.0 \\
\frac{\bar{\varepsilon}_{m b, 95) C I R}}{\varepsilon_{y}}=\frac{\left(0.93+P / P_{y}\right)^{1.71} \bar{\lambda}^{0.31}}{R_{t}^{1.06}} \pm 3.04 \leq 20.0 \text { (6) }
\end{gathered}
$$

valid for the ranges, $0.05 \leq R_{t} \leq 0.09,0.2 \leq \bar{\lambda} \leq 0.6$ and $0.0 \leq P / P_{y} \leq 0.2$.

The dashed lines in Fig.9 are the lower bound and upper bound levels for the proposed equations and it is recommended here, to select the lower bound values from Eq.(5) and (6) which will provide the minimum ultimate strain for the steel circular columns under UNI and CIR loading. In these equations maximum limit for ultimate strain is set to 20.0 because, in case of large ultimate strain, low cycle fatigue may initiates in the material. In the other words, 


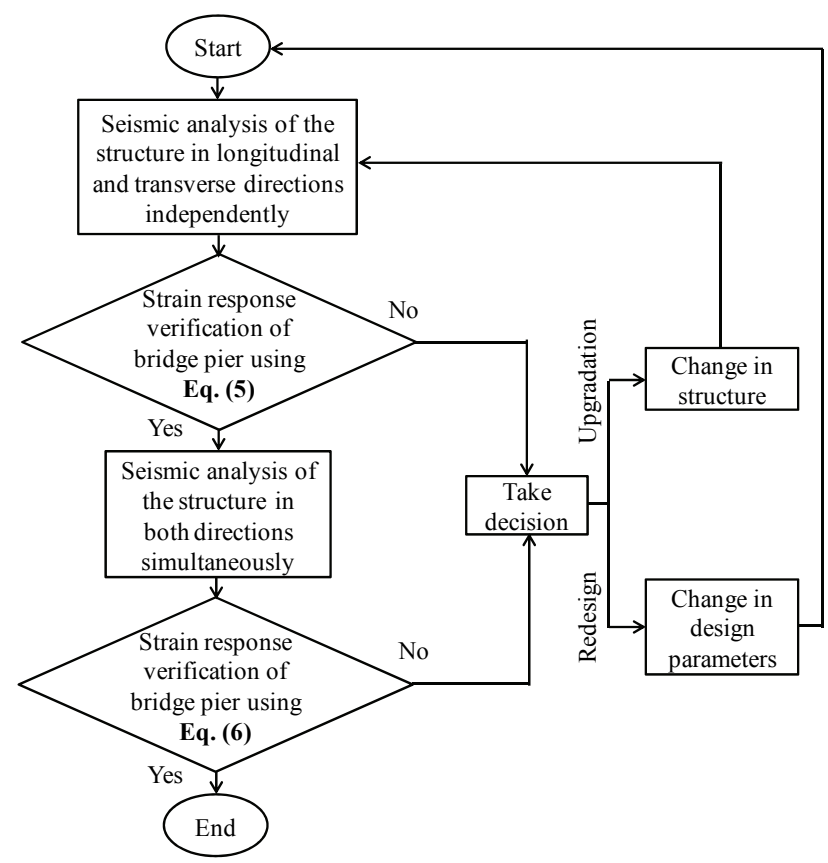

Fig.10 Procedure of strain-based seismic verification method.

ultimate strain which is in fact an average compressive strain, if exceeds this limit, the local maximum strain would be very large and such numerical results would become unreliable. Hence, the upper bound for ultimate strain is limited to $20.0^{25)}$.

\section{b) Seismic verification method}

It is well known that, the earthquake generates multidirectional motions in the ground; therefore, it is important to verify structural response due to more than one simultaneous earthquake components. Similar to the previously proposed displacement-based seismic verification method ${ }^{15)}$, the strain-based verification method is proposed here with considering the ultimate strain equations for UNI and CIR loading i.e. Eq.(5) and Eq.(6). The step by step procedure of this method is indicated in Fig.10 and explained as follows,

(1) In the first step, similar to the conventional uni-directional verification method, apply the earthquake motions in longitudinal and transverse directions to the structure and check whether the maximum response of average compressive strain in the effective failure region $L_{e}$, of the column remains within the ultimate strain calculated by the Eq.(5).

(2) If the column confirms the step (1), then apply earthquake motions in both directions simultaneously, and again check that the maximum average compressive strain response is less than the ultimate strain value from the Eq.(6).

(3) At any step, if the column fails to satisfy verification check then it is recommended to upgrade or redesign the column.

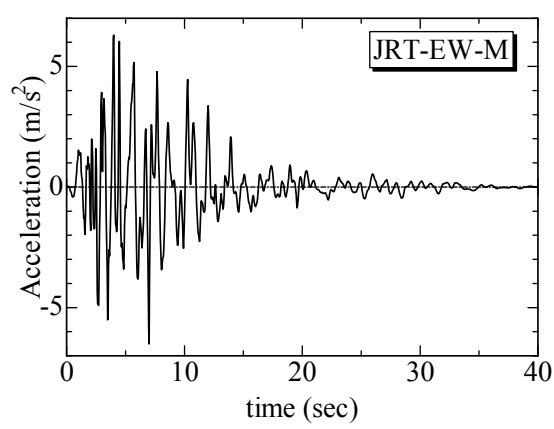

(a) EW directional

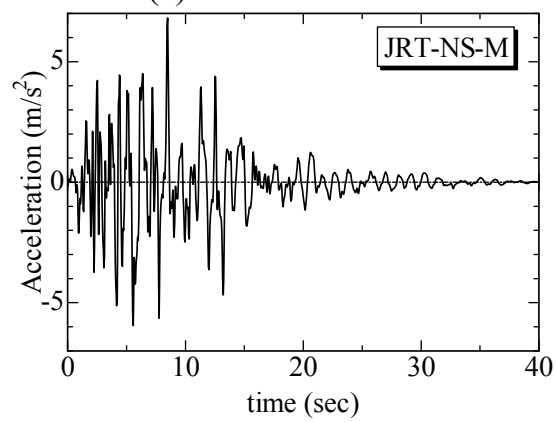

(b) NS directional

Fig.11 Earthquake components used for dynamic analysis.

The applicability of this strain-based seismic design method and comparison with the formerly proposed displacement-based design method, are explained through some illustrative examples of nonlinear dynamic analysis, in the following sections.

\section{(4) Verification of proposed seismic design method by nonlinear dynamic analysis}

Nonlinear dynamic analyses are performed to explain the functionality of strain-based seismic verification method which is proposed in this study and at the same time comparing this method with former displacement-based verification method ${ }^{15)}$. Three cases of single bridge pier are selected here as: P60-20 (where, P60-20 means a pier having $R_{t}=$ 0.060 and $\bar{\lambda}=0.2$ ), P60-40, P60-60, which have different slenderness ratio but same radius-thickness ratio. Beam element model as shown in Fig.1(b), with concentrated mass at the top of the pier are constructed and modified two-surface model is used to simulate the cyclic behaviour of steel material.

Rayleigh damping, which usually appears in the dynamic analysis, consists of mass proportional and stiffness proportional damping coefficient. Mass proportional damping coefficient $\alpha$ is calculated for each pier based on their respective fundamental frequencies. Eigenvalue extraction analysis is performed to evaluate natural frequencies and corresponding mode shapes. First 10 modes are selected which ensures the total effective mass in each direction is more than $90 \%$ of total mass of the structure. 


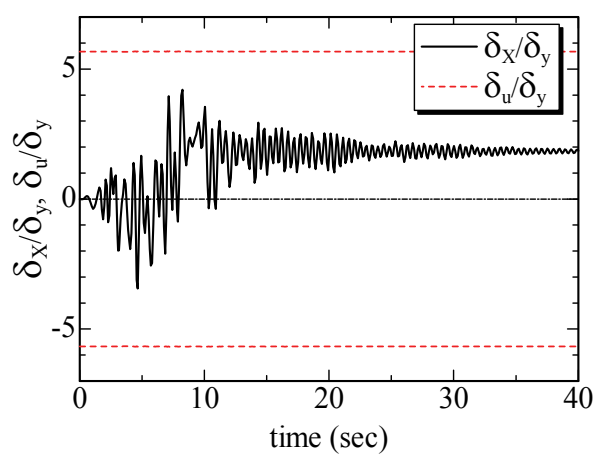

(a) EW directional displacement response

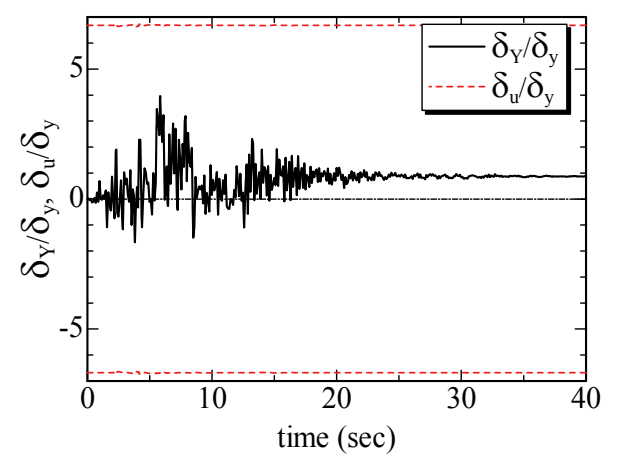

(b) NS directional displacement response

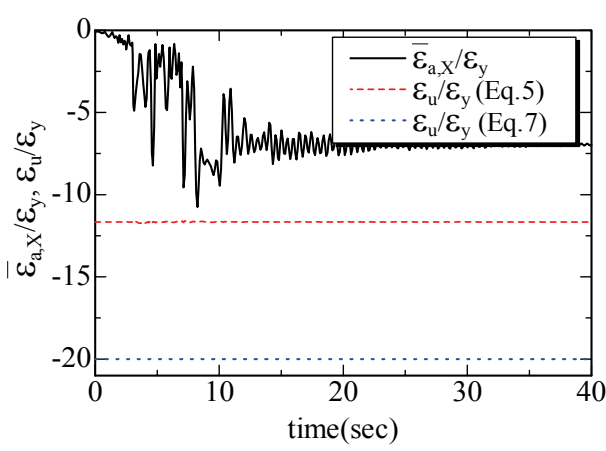

(c) EW directional strain response

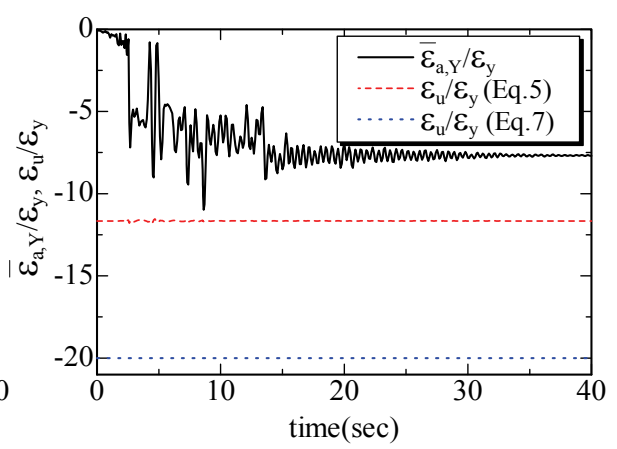

(d) NS directional strain response

Fig.12 Uni-directional seismic response verification for P60-40 due to EW and NS earthquake components (Initial design).

Stiffness proportional damping coefficient $\beta$ is not considered in these dynamic analysis. However, the hysteretic damping comes into action because of material nonlinearity.

In the dynamic analysis, before applying the actual earthquake components, gravity forces are made activated on the pier including concentrated mass at the top. Since, this pier model is assumed to be isolated from rest of the bridge system, mass at the top gets vibrated like a cantilever structure during the earthquake. Two kinds of strong earthquake components on Ground type $\mathrm{II}^{3)}$, JRT-EW-M and dynamic analyses are performed for three cases of the piers but, the results only for pier P60-40 are discussed here. JRT-NS-M as shown in Fig. 11 are selected. The dynamic analyses are performed for three cases of the piers but, the results only for pier P60-40 are discussed here.

\section{a) Dynamic response of pier P60-40}

As described in the strain-based verification method, at first EW and NS earthquake components are independently applied on the pier P60-40, and response-histories are observed for displacement of top of the pier $\left(\delta_{X} / \delta_{y}\right.$ and $\left.\delta_{Y} / \delta_{y}\right)$ and average compressive strain in the effective failure region $\left(\bar{\varepsilon}_{a, X} / \varepsilon_{y}\right.$ and $\left.\bar{\varepsilon}_{a, Y} / \varepsilon_{y}\right)$ as shown in Fig.12. The displacement response-histories are found to be bounded between ultimate displacement limits $\delta_{u} / \delta_{y}{ }^{15)}$ shown by red dashed line in Fig.12(a) and (b), which confirms that displacement response of pier is safe during individual earthquake component. In Fig.12(c) and (d), the average compressive strain time-histories are checked against two ultimate strain limits $\left(\varepsilon_{u} / \varepsilon_{y}\right)$, one is defined by the Eq.(5) and the other is given in Eq.(7), which is the strain-based allowable solution available from past study ${ }^{8)}$.

$$
\frac{\varepsilon_{u}}{\varepsilon_{y}}=\frac{0.14\left(1.1-P / P_{y}\right)^{1.8}}{\left(R_{t}-0.03\right)^{1.4}}+\frac{3}{\left(1.1+P / P_{y}\right)^{0.7}} \leq 20.0
$$

valid for the range $0.03 \leq R_{t} \leq 0.50,0 \leq P / P_{y} \leq 1.0$

It should be noted that Eq.(7) was derived from the parametric study by applying combined compression and bending loading on steel circular sections which neglect the effect of entire height of the column therefore, slenderness ratio term is not appeared in this expression.

Fig.12(c) and (d) indicate that one directional earthquake response-histories of average compressive strain are within both ultimate strain limits defined by Eq.(5) and (7) and hence, confirm the first step of seismic verification method. In addition, it is observed that Eq.(5) calculates smaller limit value to check safe performance of pier than that of Eq.(7), which means the ultimate strain formula defined for uni-directional loading, gives critical design for bridge piers. Here, critical designing stands for the minimum plate thickness (i.e. radius-thickness ratio) of bridge pier for given height and mass due to su- 


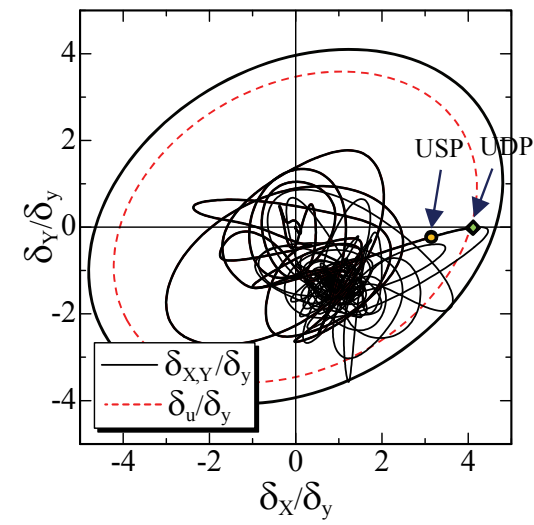

(a) EW-NS directional displacement response

(b) EW-NS directional strain response

Fig.13 Bi-directional dynamic response verification for P60-40 due to EW-NS earthquake components (Initial design).

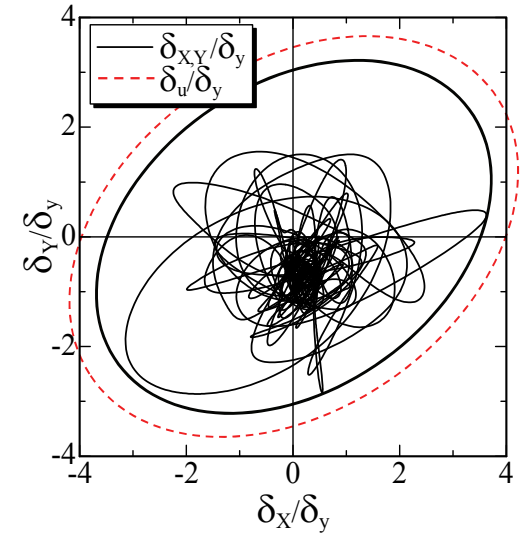

(a) EW-NS directional displacement response

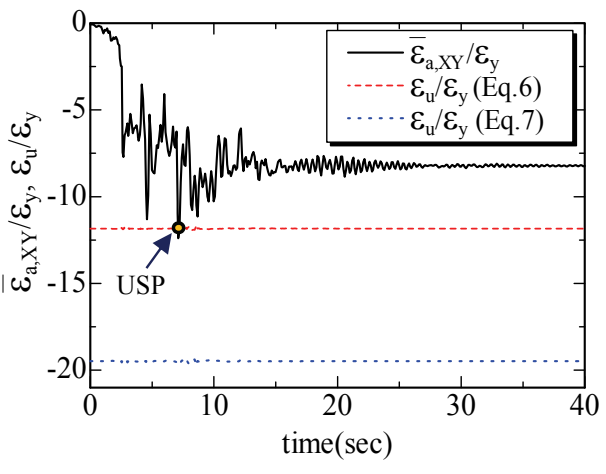

(b) EW-NS directional strain response

Fig.14 Bi-directional dynamic response verification for P60-40 due to EW-NS earthquake components (Trail-1 design).

perstructure, whose seismic performance remains within lowest allowable limit.

In the next step, dynamic analysis is performed by applying EW and NS components of the earthquake at the same time. The displacement-based verification method developed in author's previous work ${ }^{15)}$, is used to check bi-directional displacement response of the pier top. Fig.13(a) shows the trajectory of displacement response, which crosses the ultimate state ellipse (shown by red dashed line). In Fig.13(b), average compressive strain response-history is found to be passed through the ultimate strain limit defined by Eq.(6) but not through the line of Eq.(7). From Fig.13 it can be said that currently designed pier P60-40 which was performed safely in individual earthquake component, is failed to satisfy the safe performance in two-dimensional earthquake components. The points denoted by UDP and USP are the time instances where displacement response and strain response trajectories crosses their respective ultimate limit lines. In currently designed pier P60-40, USP appears earlier than UDP which apparently indicates that strain-based verification method provides critical seismic design than displacement-based method. Therefore to verify this hypothesis, redesign option given in the verification method (see Fig.10) is selected.

Ideally in the design practices, redesign means to alter the radius-thickness ratio i.e. the plate thickness of the pier, because height of the pier and the lumped mass at the top due to superstructure are predefined and remain unchanged in each modification of the design step. However, in the present case it is decided to keep the geometrical properties of pier same in each alteration because, if pier dimensions are changed then it will not be feasible to maintain consistency in comparison of performances in different steps of redesigning. For example, in one step of seismic verification, pier P60-40 (i.e. $R_{t}=0.06, \bar{\lambda}=$ $0.4)$ shows unsafe performance and hence in next step, if $R_{t}$ changes to 0.05 then it will become P50-40 pier which has different geometrical properties than former pier. Therefore, instead of changing $R_{t}$, the lumped mass at the top is adjusted so as to expect performance of the pier enough to be safe when subjected to bi-directional earthquake. This step is named as Trail-1. The bi-directional dynamic analysis is carried out and the displacement and strain 


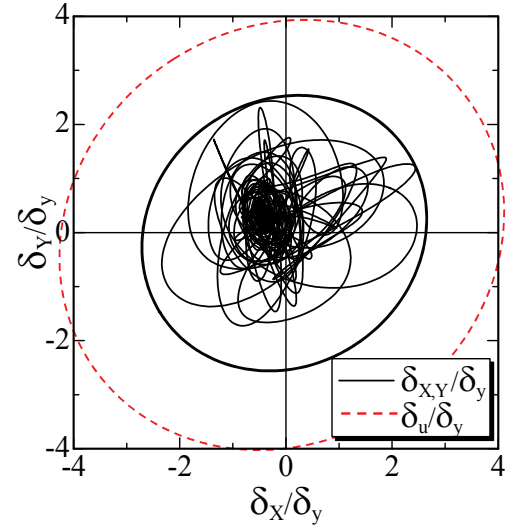

(a) EW-NS directional displacement response

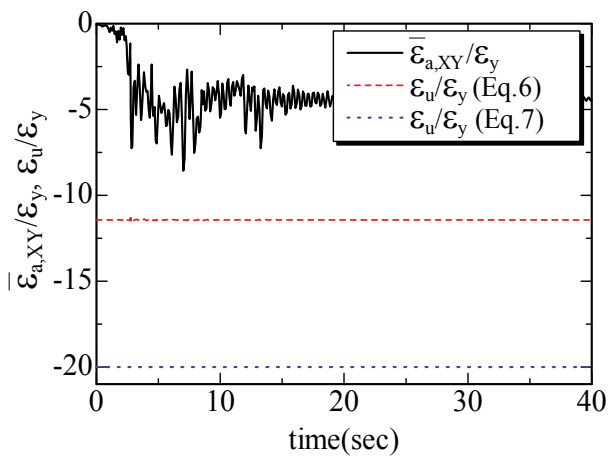

(b) EW-NS directional response

Fig.15 Bi-directional dynamic response verification for P60-40 due to EW-NS earthquake components (Trail-2 design).

response-histories are plotted as illustrated in Fig14. The pier designed for Trail-1 step has shown safe performance with respect to displacement verification (see Fig.14(a)), but still failed to satisfy strain criteria and USP is appeared when strain response crosses the ultimate strain line (see Fig.14(b)) which means strain-based verification provides minimum allowable limit than that of displacement-based method.

In the next step which is called as Trial-2, pier P60-40 is redesigned again by changing the lumped mass and then analyzed for bi-directional earthquake. Displacement and strain responses are checked against their respective ultimate limits as indicated in Fig.15. In this step, it is noticed that the pier P60-40 has shown safe response with respect to both displacement and strain criteria.

Above mentioned uni-directional and bi-directional dynamic analysis steps are carried out for other two piers: P60-20 and P60-60. These piers have also shown similar behaviour with that of pier P60-40 in each step and proved that strain-based method is a critical verification method. Moreover, it is verified that ductility formulas derived in the present study i.e. Eq.(5) and (6) provide lower limit values of ultimate strain in comparison with formula developed in the past study i.e. Eq.(7). Hence, these observations indicate that, strain-based seismic verification process developed in the present study, designs the bridge piers in such a way that they can assure safe performance in severe conditions generated due to coupling of two horizontal earthquake components.

\section{CONCLUSIONS}

The seismic verification method based on strain ductility formulas is proposed in the present work which is useful when two horizontal earthquake components are applied independently or simultaneously.

Two types of FE models made up of shell element and beam element are analysed for uni- as well as bi-directional horizontal cyclic loadings considering the material and geometric nonlinearities. The observation of strength envelop curves have indicated that, both radius-thickness ratio and slenderness ratio including type of loading pattern have unavoidable impact on maximum strength values and slope of post peak curves. The effect of gradually varying loading patterns on the ultimate strain of two types of FE models has shown similar behaviour and pointed out that the slenderness ratio parameter $(\bar{\lambda})$ plays an important role in the ultimate behaviour of the steel circular columns and hence, necessary to include in the ductility formulation.

The ultimate strain formulas developed in the present work are based on the observations of ultimate strain in the beam element model because this ensures synchronization between the FE modelling techniques used in capacity and demand prediction methods.

The applicability of proposed ultimate strain formulas in the seismic verification method is compared with formerly developed displacement-based method and also with the ultimate strain formulation defined in past research by conducting nonlinear dynamic analysis on three different piers. The results revealed that, even if the performances of certainly designed piers are found to be safe under uni-directional earthquake component, they may fail to secure their displacement and strain responses when bi-directional earthquake components are applied. This implies that, pier responses are considerably increased due to bi-directional earthquake 
components and hence it is very important to design bridge piers for simultaneously applied two directional earthquake components. The dynamic analysis on redesigned piers has shown that, bi-directional strain-based verification method is critical and easier in application than that of displacement-based method.

Comparison between ultimate strain formulas derived in the past study and present work, has indicated that formulas from present work provide minimum ultimate strain value in both cases when earthquake components are applied in one direction and two directions simultaneously. Hence, the ductility formulas given in this study are more adequate for use in seismic verification process of steel circular bridge piers, as these formulas are based on all important parameters which govern the design of steel circular bridge piers.

\section{REFERENCES}

1) Bruneau, M. : Performance of steel bridges during 1995 Hyogoken-Nanbu (Kobe, Japan) earthquake-A North American perspective, Eng. Struct., Vol. 20, No. 4, pp. 1063-1078, 1998.

2) Japan Road Association : Specification for highway bridges-Part V Seismic design, Tokyo, Japan, 1996.

3) Japan Road Association : Specification for highway bridges-Part V Seismic design, Tokyo, Japan, 2002.

4) Kawashima, K. and Unjoh, S. : Seismic design of highway bridges, J. Japan Assoc. for Earthquake Eng., Vol. 4, No. 3, pp. 174-183, 2004.

5) Usami, T. and Ge, H. B. : A performance-based seismic design methodology for steel bridge systems, J. Earthquake and Tsunami, Vol. 3, No. 3, pp. 175-193, 2009.

6) Gao, S., Usami, T. and Ge, H. B. : Ductility of steel short cylinder in compression and bending, J. Eng. Mech., ASCE, Vol. 124, No. 2, pp. 176-183, 1998a.

7) Zheng, Y., Usami, T. and Ge, H. B. : Ductility of thin-walled steel box stub-columns, J. Struct. Eng., ASCE, Vol. 126, No. 11, pp. 1304-1311, 2000.

8) Ge, H. B., Kono, T. and Usami, T. : Failure strain of steel segments subjected to combined compression and bending and application to dynamic verification of steel arch bridges, J. Strct. Eng., JSCE, Vol. 50A, pp. 1479-1488, 2004 (In Japanese).

9) Gao, S., Usami, T. and Ge, H. B. : Ductility evaluation of steel bridge piers with pipe sections, J. Eng. Struct., ASCE, Vol. 124, No. 3, pp. 260-267, 1998 b.

10) Usami, T. and Ge, H. B. : Cyclic behavior of thin-walled steel structures-numerical analysis, Thin-walled Struct., Vol. 32, pp. 41-80, 1998.
11) Anderson, E. L. and Mahin, S. A. : An evaluation of bi-directional earthquake shaking on the provisions of the AASHTO guide specifications for seismic isolation design, Proc. of 13th World Conference on Earthquake Eng., Vancouver, British Columbia, Canada, Paper No. 763, 2004.

12) Okazaki, S., Usami, T. and Kasai, A. : Elasto-plastic dynamic analysis of steel bridge piers subjected to bi-directional horizontal earthquake, J. Struct./Earthquake Eng., JSCE, Vol. 27, pp. 1-8, 2003 (In Japanese).

13) Watanabe, E., Sugiura, K. and Oyawa, W. O. : Effect of multi-directional displacement paths on the cyclic behavior of rectangular hollow steel columns, Struct. Eng./Earthquake Eng., JSCE, Vol. 17, No. 1, pp. 79-94, 2000.

14) Goto, Y., Jiang, K. and Obata, M. : Stability and ductility of thin-walled circular steel columns under cyclic bi-directional loading, J. Struct. Eng., ASCE, Vol. 132, No. 10, pp. 1621-16231, 2006.

15) Kulkarni, N. G., Kasai, A. and Tsuboi, H. : Displacement based seismic verification method for thin-walled circular steel columns subjected to bi-directional cyclic loading, Eng. Struct., Vol. 31, No. 11, pp. 2779-2786, 2009.

16) Dussault Systems Simulia Corp. : Abaqus/Standard user's manual 6.7-5. Providence, RI, USA, 2007.

17) Shen, C. : Development of cyclic two-surface model for structural steels with yield plateau, Ph. D. thesis, Dept. Civil Eng., Nagoya University, Nagoya, Japan, 1993.

18) Mamaghani, I. H. P., Shen, C., Mizuno, E. and Usami, T. : Cyclic behavior of structural steel. I: Experiments, J. Eng. Mech., ASCE, Vol. 121, No. 11, pp. 1158-1164, 1995.

19) Shen, C., Mamaghani, I. H. P., Mizuno, E. and Usami, T. : Cyclic behavior of structural steel. II: Theory, J. Eng. Mech., ASCE, Vol. 121, No. 11, pp. 1165-1172, 1995.

20) Mamaghani, I. H. P., Usami, T. and Mizuno, E. : Inelastic large deflection analysis of structural steel members under cyclic loading, Eng. Struct., Vol. 18, No. 9, pp. 659-668, 1996.

21) Usami, T., et al. : Guidelines for Seismic and Damage Control Design of Steel Bridges, Gihodo Publications, Tokyo, 2006, (In Japanese).

22) Goto, Y., Muraki, M. and Obata, M. : Ultimate state of thin-walled circular steel columns under bidirectional seismic accelerations, J. Struct. Eng., ASCE, Vol. 135, No. 12, pp. 1481-1490, 2009.

23) Ge, H. and Usami, T. : Cyclic tests of concrete-filled steel box columns, J. Struct. Eng., ASCE, Vol. 122, No. 12, pp. 1169-1177, 1996.

24) Dussault Systems Simulia Corp. : Abaqus/CAE 6.7-5. Providence, RI, USA, 2007.

25) Usami, T., Zheng, Y. and Ge, H. B. : Resent research development in stability and ductility of steel bridge structures General Report, J. Constructional Steel Research, Vol. 55, pp. 183-209, 2000.

(Received January 28, 2011) 